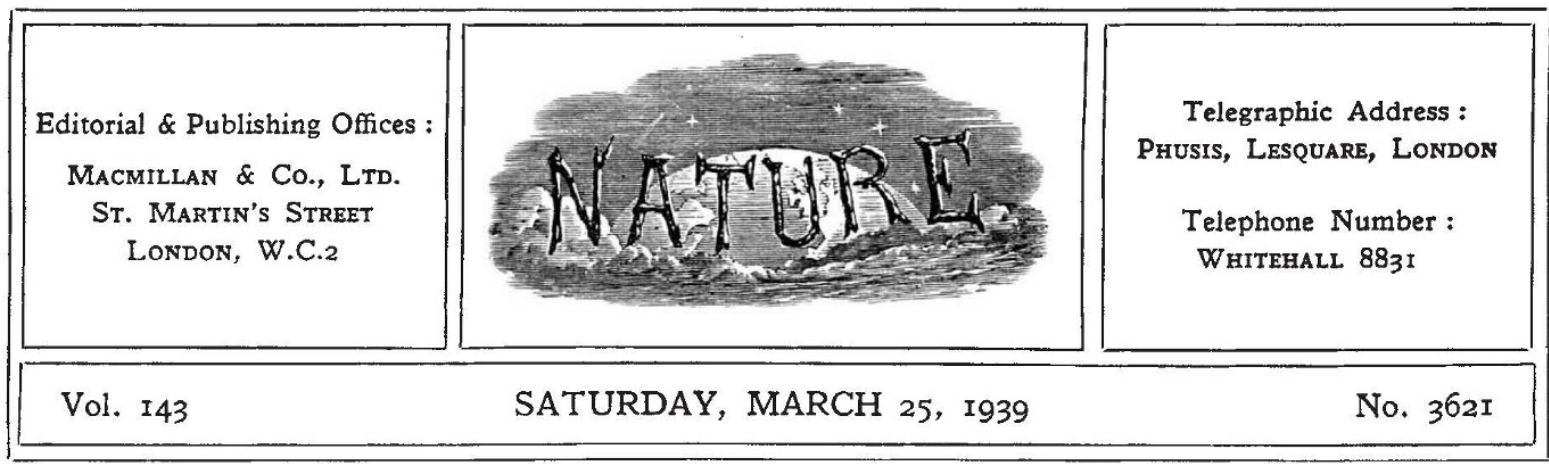

\title{
Scientific and Industrial Research in Great Britain
}

W ITH the increase in the number of reports issued by individual boards or departments under the Department of Scientific and Industrial Research, the value of the Department's own report, a survey of which appears on p. 499 of this issue, and especially that of the Advisory Council, is enhanced rather than diminished. Apart altogether from the broad picture it gives of the manysided contributions made by the Department to the welfare of the whole nation, it has become increasingly a vehicle for the discussion of the more fundamental problems of co-operative scientific and industrial research, and of the factors upon which success or failure in this field depend.

An important section of the report of the Advisory Council is this year devoted to the position of the research associations, and this discussion is of the greater interest in view of the recently published report of the Parliamentary Science Committee on the Finance of Research (referred to in Nature of January 28). Indeed it may be said that, taken as a whole, the report of the Department supplies a much more convincing answer to the arguments of that report than those in the observations of the Advisory Council on, and published with, that report. The practice of the Department is even more reassuring than the arguments advanced by the Advisory Council in defence of the policy upon which that practice is based. The straightforward narrative of the achievements of the Department contains encouraging evidence of flexibility and foresight, and some attempt to diminish those fluctuations of income which have such an adverse effect alike upon the conduct of long-range investigations and on the work of the staff responsible for their conduct.

Five years ago, the major part of the report of the Advisory Council was devoted to a historical review of the research association scheme for developing the application of science by industry in Great Britain, and its criticism of the movement was directed to the inadequate scale on which it was financed. Recommendations then made for remedying this weakness were accepted by the Government, but subsequent discussions with the various associations led the Advisory Council to believe that to encourage them to embark on operations on a more adequate scale the basis on which grants were made must be definitely shaped with that primary purpose. Accordingly the Council recommended that the Department offer block grants of so substantial an amount that, with the contributions from industry upon which they should be conditional, they would secure an income adequate for each association to develop a really effective organization. To encourage further development, the Council recommended additional grants, on a sliding scale, within prescribed limits, on all income raised from industry in excess of a specified figure. The amounts of the minimum income, the specified figure and the limit of the grant were to be determined on the morits and needs of each case, and the normal period of these new arrangements was to be five years. The success of this plan is shown by an increase of nearly forty per cent in the total sum subscribed annually by industry on the amount provided before it came into operation, although it has to be admitted that that sum is still only a little more than a quarter of a million pounds.

The Advisory Council has now again reviewed the whole position, and arrangements have been made by which consideration of individual research associations will be spread over several years, thus keeping the general scheme under inspection and securing a thorough periodical examination 
of each individual association. It is proposed to make a detailed review of the work and progress of each association at the end of the particular five-year period for which its grant has been made, before recommending grants for a further period.

This arrangement has brought under review in the present report the Wool Industries Research Association and the research association of the iron and steel industry. Grants have also been made to the newly formed British Coal Utilisation Research Association. The comments in the report of the position of these and other associations deserve some note as indicating some of the general tendencies and weaknesses of the research association movement.

It will be remembered that in observations on the memorandum of the Parliamentary Science Committee on the Finance and Development of Research, the Advisory Council reiterated the view which was expressed in its report for 1930-31 that the expenditure on research which is defensible in the national interest depends on the degree to which industry generally is prepared to apply scientific method and advances in scientific know. ledge. The position of the Wool Industries Research Association illustrates the limitations and defects of that method. The admirable work already conducted at Torridon, with the light which it has thrown, for example, on the fundamental structure of animal fibres, has earned for the Association a high scientific reputation, and the fundamental knowledge and technique thus acquired have found application in fields well beyond the bounds of the woollen industry. It cannot accordingly be regarded as entirely satisfactory that such important contributions to the general body of scientific knowledge should be retarded by the failure of an industry to appreciate the importance of research.

It is, of course, realized that only an industry that is thoroughly research-minded can be expected to support such fundamental research, the bearing of which upon manufacturing technique or development is not immediately apparent. If, however, there is any force in the contention that fundamental or long-range research is pre-eminently the field of the research association, as distinct from the research departments of individual forms, the present policy of the Advisory Council has obvious limitations and design. That this is realized by the Advisory Council is indeed shown by its own recommendations in regard to the British Boot, Shoe and Allied Trades Research Association.
Failure of this Association to obtain and maintain

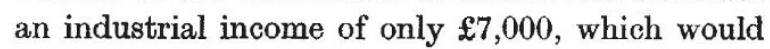
have secured a total income of $£ 12,000$, led to it operating for two years without a grant. Impressed by the special limitations in the field of work open to this Association, owing to the almost complete monopoly in the supply of machinery to the industry, and in view of the importance of shoeefficiency to the national health, the Advisory Council as an exceptional measure has recommended an offer of renewed grant aid which will secure for the Association a minimum income of $\mathfrak{1 8 , 0 0 0}$ a year with a possibility of $\mathfrak{1 2 , 0 0 0}$.

In a recent letter (NATURE, 143, 336 ; Feb. 28, 1939), Dr. W. H. Gibson stressed the inuportance of consideration of the position of research associations in a scientific spirit, and directed attention to some of the limitations which are commonly imposed on their work. If they are to confine themselves to research on the processes of their members, they will be limited in their work essentially to those fields which are the natural territory of the research departments of the individual firms. This means further limitation of the fundamental research which is the basis of all major industrial advance, but which is often beyond the resources of all but the very largest of industrial units, and indeed it may be added, is often a tax upon the resources of the best-equipped university departments, to which alone we can look further for assistance. It may be noted that the large industrial firms often prefer to support such investigations by specific grants to a university department rather than to embark on them in their own laboratories.

Even, however, if we could safely rely on the universities for the fundamental research which is required for the advance of industry - and there are very definite limits to the extent to which research at a university should be dictated even by national needs, let alone the requirements of industry - it is obviously unreasonable, if not impossible, to expect them to provide for a further need to which Dr. Gibson directed attention. Dr. Gibson stressed the importance of research upon the raw materials themselves, the price of which often constitutes a large proportion of the price of the finished article. Unless and until attention is paid to ensuring ample supplies of uniform quality and reasonable price, no amount of research on processes will overcome the difficulties of British industry.

Equally important is research in developing entirely new uses for raw materials outside existing 
channels. Many notable advances have originated from the use of some raw material for a new purpose. Under present conditions, a research association which is working for members who are operating established processes cannot embark on such investigations. Accordingly a most fruitful field lies neglected and unfinanced.

As we have repeatedly urged in these columns, what is required is a scientific approach to the whole problem, and the orientation and distribution of the national research effort in accordance with a comprehensive survey of the resources available. This is essential, apart altogether from the question of the magnitude of the total effort or even of the relative contribution of industrial or national sources. Only as we can assess with some degree of accuracy the contribution which is being made in different fields and from different sources can we make any sound decision as to the magnitude of the contribution which should come from the national revenue. The observations of the Advisory Council on the position of the research associations emphasize the need for this comprehensive survey and for some attempt to delineate broadly the field between the various research organizations - private enterprise, research associations, Government research stations and the universities.

An authoritative survey of this type could scarcely be undertaken except under Government initiative and authority, although it is possible that something on these lines might come within the field of the newly formed Division for the Social and International Relations of Science of the British Association. At least it might facilitate the scientific approach to the problem which is badly needed, and the enunciation of principles upon which increased Government grants for scientific research could be indubitably justified, whether to the universities themselves, to Government research stations or institutions or to the research associations.

A step of this kind should not be without effect on a further aspect of the situation to which Dr. Gibson also directed attention-the position of the scientific worker. The great divergencies which exist between the position of scientific workers engaged in essentially similar duties in the universities, Government establishments, private firms and research associations are not to be defended. Co-operative research associations which are supported in part by an industry are at a disadvantage in retaining an experienced staff as compared with an industry which for some reason or other may make no contribution towards co-operative rezearch, either getting it done by a Government establishment or relying on individual and private effort. The results achieved in co-opsrative research depend not merely on the financial resources at the disposal of the research associa. tions but also on the calibre of their scientific and technical staff. If the conditions of service are so inferior in remuneration or security to those which obtain elsewhere that they cannot compete on equal terms with private industry or Government departments in recruiting their staff, the quality of their work must ultimately be lowered.

The importance of this question to the industries concerned, no less than to the nation itself, need scarcely be stressed in view of the past achieve. ments of the research association movement. It deserves closer attention than it has yet received from the professional associations of scientific workers, and any comprehensive survey and analysis of the research effort of the nation should have reference to this problem also. It should not be forgotten, of course, that mobility of staff within limits has its own advantages in stimulating the exchange of technique and ideas. A definite drawback of pension schemes is in fact the indirect discouragement which they give to the movement of staff, and there are other factors which in recent years have discouraged the movement of scientific workers from one firm to another, whether within the same industry or not. Such movement may be stimulating in ideas and technique as well as facilitating the growth of a wider judgment or experience of great value in the direction of research in industry and Government service.

A more liberal policy in regard to the exchange of pension rights might well prove a sound invest. ment both to Government services and industry, and it should not prove beyond the national resources to devise some means of eliminating that factor of insecurity of tenure which in other fields of research besides that of the research associations tends to affect adversely the recruitment of scientific staff of the highest quality. Certain it is that if the research association movement is to find a definite place in the national organization for research, it will only make its full contribution if the same careful consideration is given to the broad fields in which it should operate, and to the conditions of recruitment and employment of its scientific and technical staff, as has been given in the past to the assessment of its financial grants. 